\title{
Veri Madenciliği Tekniklerinin ve Algoritmik Araştırmaların Hadis İlmine Uygulanabilirliği
}

\author{
Sema Tombul \\ Arş. Gör., Sivas Cumhuriyet Üniversitesi (ROR ID: 04f81fm77) \\ İlahiyat Fakültesi, Hadis Anabilim Dalı \\ Research Assistant, Sivas Cumhuriyet University, Faculty of Theology, Department of Hadith \\ Sivas/Turkey \\ stombul@cumhuriyet.edu.tr \\ ORCID: 0000-0003-3622-5407
}

\section{Applicability of Data Mining Techniques and Algorithmic Research to the Science of Hadith}

\begin{abstract}
In this digital age, the presence of information is felt more and more day by day. When this information circulating in the digital environment is processed and transformed into a highquality form, it will be able to serve for the developing technology age. At this point, data mining methods and algorithmic research that process large amounts of information come into play. Data mining is one of the technologies that is applied and will might be utilized in many fields including natural and social sciences. Such studies, which appear in many scientific disciplines, have also been carried out in the field of hadith, especially within the last twenty years. In this study, the most cited scientific articles that apply data mining methods and algorithmic research to the science of hadith in the world were examined. The studies carried out so far have focused on the the text of the hadith, its rawi (narrator), its authenticity or its use in the web environment. Some of these studies aim to classify the hadiths according to their subjects in general and to create hadith dictionaries in particular. On the other hand, there are studies to systematize the authenticity of the hadith by formulating the chain of narrators and the authentic hadith. In addition there are some studies that evaluate narrators by creating social network graphics. These researches offer the opportunity to present the data in the hadith in a computable and objective way by structuring, as in the sciences. In fact, the hadith scholars (muhaddiths), who aimed to prevent the oblivion and destruction of the sunnah centuries ago, tried to measure and evaluate the knowledge they had acquired on the hadith. From these muhaddiths, we have received some subjective, which are sometimes agreed upon, and sometimes individual evaluations about both the rawi and the text of the hadith. At this point, data mining techniques and algorithmic research will sometimes turn interpretation-based and repetitive information into concrete data. Another opportunity
\end{abstract}

Intihal Taraması/Plagiarism Detection: Bu makale intihal taramasından geçirildi/This paper was checked for plagiarism Etik Beyan/Ethical Statement: Bu çalışmanın hazırlanma sürecinde bilimsel ve etik ilkelere uyulduğu ve yararlanılan tüm çalışmaların kaynakçada belirtildiği beyan olunur/It is declared that scientific and ethical principles have been followed while carrying out and writing this study and that all the sources used have been properly cited (Sema Tombul).

Geliş/Received: 01 Temmuz/July 2021 | Kabul/Accepted:06 Eylül/September 2021 | Yayın/Published: 20 Eylül/September 2021

Atıf/Cite as: Sema Tombul, "Veri Madenciliği Tekniklerinin ve Algoritmik Araştırmaların Hadis İlmine Uygulanabilirliği = Applicability of Data Mining Techniques and Algorithmic Research to the Science of Hadith", Eskiyeni 44 (Eylül/September 2021), 461-474. https://doi.org/10.37697/eskiyeni.960636

CC BY-NC 4.0 | This paper is licensed under a Creative Commons Attribution-NonCommercial License 
offered by these studies is that the people who access the hadith text from the digital environment gain the awareness of obtaining information about the content of the hadith data. As a matter of fact, as seen in some studies, anti-hadith websites are frequently visited by students who want to learn about hadith. For this reason, managing the information sources that the public reaches will help to solve many social and political problems arising from the wrong perception of religion. The aim of this work is to introduce data mining and algorithmic research to scholars in the field of hadith in Turkey and to use these techniques together with the science of hadith to enable scholars to contribute to the field of hadith.

\section{Keywords}

Hadith, Algorithm, Data Mining, Text Mining, Social Network Analysis

\section{Veri Madenciliği Tekniklerinin ve Algoritmik Araştırmaların Hadis İlmine Uygulanabilirliği}

\section{Öz}

Çağımızda bilginin dijital dünyadaki varlığı her geçen gün daha çok hissedilmektedir. Dijital ortamda dolaşan bu bilgiler işlenip nitelikli bilgiye dönüştürüldüğünde gelişen teknoloji çağına katkı sunacaktır. Bu noktada büyük miktardaki bilgiyi yapılandıran veri madenciliği yöntemleri ve algoritmik araştırmalar devreye girmektedir. Veri madenciliği, fen bilimlerinden sosyal bilimlere birçok sahada kullanılan ve kullanılması muhtemel yöntemlerden biridir. Pek çok ilmî disiplinde karşımıza çıkan bu yöntemlerin özellikle son yirmi yıldır hadis alanında da yapıldığı görülmektedir. Bu çalışmada dünya üzerinde veri madenciliği yöntemlerini ve algoritmik araştırmaları hadis ilmine uygulayan ve en çok atıf alan bilimsel makaleler incelenmiştir. Şu ana kadar yapılan çalışmalar hadisin metnine, ricâline, sıhhatine yahut web ortamındaki kullanımına odaklanmaktadır. Bu araştırmaların bir kısmı genel olarak hadisleri konularına göre tasnif etmeyi, özel olarak hadis sözlükleri oluşturmayı hedeflemektedir. Öte yandan seneddeki râvi zincirini ve sahih hadisi formüle ederek hadisin sıhhat tespitini sistemleştirmeye yönelik çalışmalar da bulunmaktadır. Ayrıca sosyal ağ grafikleri oluşturmak suretiyle râviler üzerine incelemelerde bulunan araştırmalara rastlanmaktadır. Bu araştırmalar fen bilimlerinde olduğu gibi hadis ilmindeki verilerin yapılandırılarak hesaplanabilir ve nesnel bir şekilde ortaya konulmasına firsat sunmaktadır. Esasında asırlar önce sünnetin unutulmasının ve tahrip edilmesinin önüne geçmeyi amaçlayan muhaddisler de hadis ilmine dair edindikleri bilgileri ölçmeye ve değerlendirmeye çalışmışlardır. Bu muhaddislerden bizlere hem hadisin ricâli hem de metni konusunda kimi zaman üzerinde ittifak edilen kimi zaman münferit öznel değerlendirmeler ulaşmıştır. İşte bu noktada veri madenciliği teknikleri ve algoritmik araştırmalar kimi zaman yoruma dayalı ve kendini tekrar eden malumatları somut verilere dönüştürecektir. Bu araştırmaların sunduğu bir diğer firsat ise hadis metnine dijital ortamdan ulaşan halkın hadis verilerinin içeriği hakkında bilgi edinme bilincini kazanmasıdır. Nitekim bazı araştırmalarda görüldüğü üzere hadis karşıtı web siteleri hadis hakkında bilgi sahibi olmak isteyen öğrenciler tarafından sıkça ziyaret edilmektedir. Bu sebeple halkın ulaştığı bilgi kaynaklarını yönetmek yanlış din algısından kaynaklanan sosyal ve politik birçok problemin çözüme kavuşturulmasına yardımcı olacaktır. Bu çalışmanın amacı özellikle Türkiye'deki hadis alanında çalışan araştırmacılara veri madenciliğini ve algoritmik araştırmaları tanıtmak ve bahsi geçen bu yöntemleri hadis ilmiyle birlikte kullanarak araştırmacıların hadis ilminin gelişimine katkıda bulunmasını sağlamaktır.

\section{Anahtar Kelimeler}

Hadis, Algoritma, Veri Madenciliği, Metin Madenciliği, Sosyal Ağ Analizi 


\section{Giriș}

Çağımızda bilgiye ulaşmanın en kolay yollarından biri internet ortamıdır. Diğer tüm İslâmî ilimlerde olduğu gibi hadise ulaşmak için de pek çok kullanıcı interneti birincil bilgi kaynağı olarak görmektedir. ${ }^{1}$ Diğer taraftan internet ortamında edinilen bilgilerin yayınlanmasına ilişkin herhangi bir yasal düzenleme olmaması, bu bilgileri kimin yaydığının ve kimlerin görüntülediğinin kontrol edilememesi birtakım endişelere sebebiyet vermektedir. Mesela İslam hukukunda bir fetvanın kaynağının ya da hadiste bir rivayetin sihhat değerlendirmesinin güvenilir temel İslam kaynaklarına dayandırılması gerekmektedir. Fakat internet ortamında yayılan ve ilmî bir dayanağı olmayan bilgiler kullanıcılarda dinî açıdan doğru olmayan kanaatler oluşturabilmektedir. İşte bu sebeple dijital dünyada devasa boyutlara ulaşan bu ham bilgileri yani verileri $^{2}$ toplamak ve bunları analiz ederek dine dair güvenilir bilgiye insanların ulaşmasını sağlamak önem arz etmektedir.

Pazarlama ve perakende alanlarında sıklıkla kullanılmakla birlikte tıp, mühendislik, endüstri ve istihbarat gibi pek çok sahada da yararlanılan veri madenciliği (ing. data mining), veri tabanlarında depolanan büyük miktardaki ham bilginin (ing. information), kişiler ya da kurumların amaçları doğrultusunda işlenip yapılandırılarak anlamlı hale getirilmesi (ing. knowledge) ve yapılandırılan bu verilerden geleceğe yönelik tahminlerde bulunma işidir. ${ }^{3}$ Hadis ilmi söz konusu olduğunda ise hadislerin metinlerine, râvilerine yahut sıhhat durumuna göre sınıflandırılması gibi konularda veri madenciliğine ait algoritmaların kullanıldığı görülmektedir.

Özellikle son yirmi yıldır dijital ortamdaki hadis verilerini yapılandırarak hadise dair güvenilir bilgileri makine öğrenmesi yoluyla insanlara ulaştırmayı hedefleyen çalışmalar dikkat çekmektedir. Bu çalışmalardan kimisi hadis metinlerinin tasnifine ${ }^{4}$ ağırlık verirken bazısı da râviler ${ }^{5}$ arasındaki ilişkileri merkeze almaktadır. Büyük çoğunluğu Arap dünyasında gerçekleşen ve Kütüb-i Sitte odaklı bu araştırmaların genel amacı algoritmalar yardımı ile metnin, senedin yahut her ikisinin yapiland1rılmasıdır. Böylece yapılandırılan bu veriler kullanılarak dijital ortamda yer alan hadis rivayetlerine dair daha nesnel bilgiler elde edilebilecektir. Öte yandan İslam'ın

1 Nor Shahriza Abdul Karim - Norzelatun Rodhiah Hazmi, “Assessing Islamic Information Quality on the Internet: A Case Of Information About Hadith”, Malaysian Journal of Library Amp; Information Science 10/2 (December 2005), 51-66; Adam Gambo Saleh - Mohammed Mai, "Assessment of the Quality of Hadith Information on the Internet”, Information Impact 6/2 (2015), 127-138. Her iki çalışmanın ortak sonucuna göre Islam Online (www.islamonline.com) hadis araştırmalarında kullanılan en popüler web sitesidir. Dikkat çeken diğer detay ise hadis karşıtı stormloader.com ve submission.org adlı web sitelerinin öğrenciler tarafından ziyaret edildiği bu iki çalışmanın ortak sonuçlarından biridir.

2 Seagate şirketinin raporuna göre, tüm dünyada 2015 'te 18 ,2 zetabayt ( $1 \mathrm{ZB}=1$ katrilyon GB, takriben 1,7 trilyon adet CD kadar yer kaplar) veri üretilirken bu miktarın 2025'te 175.8 zetabayt olacağı öngörülmektedir. bk. Seagate, "Rethink_Data_Report_2020” (Erişim 3 Haziran 2021).

3 Serkan Savaş vd., “Veri Madenciliği ve Türkiye'deki Uygulama Örnekleri”, İstanbul Ticaret Üniversitesi Fen Bilimleri Dergisi 11/21 (Bahar 2012), 1-23.

4 Mohammed Naji Al-Kabi vd., “Al-Hadith Text Classifier”, Journal of Applied Sciences 5/3 (2005), 584-587.

5 Sekti Kartika Dini vd., "Sequential Pattern Mining of Rawi Hadis (Case Study: Shahih Hadis of Imam Bukhari From Software Ensiklopedi Hadis Kitab 9 Imam)”, AIP Conference Proceedings 1827/1 (2017), 1-8. 
temel kaynaklarından kabul edilen hadisin web sayfalarında sahîh, zayıf yahut mevzû kaydı konulmadan yer alması bazı araştırmacıları, internet kullanıcılarına bu verilerin sıhhat değeri hakkında bilgi vermeye yönelik çalışmalara sevk etmiştir. ${ }^{6}$

Arap dünyası dışında özellikle Malezya ve Endonezya'daki hadis tercümesine odaklanan bilimsel çalş̧malar ${ }^{7}$ ve devlet destekli projeler ${ }^{8}$ Türkiye için örnek teşkil etmektedir. Nitekim yaptığımız araştırmalarda görüldüğü kadarıyla ülkemizde hadisleri bir veri olarak sisteme işleyen nadir çalışmalar ${ }^{9}$ olmakla birlikte bunların akademik bir arka planı bulunmamaktadır. Esasında bu durum yalnızca hadis alanı için söz konusu değildir. Zira algoritmaların sosyal bilimlere uygulanması ülkemizde yeni yeni görülmektedir.

Bu makalede veri madenciliği ve algoritma araştırmaların hadis alanına uygulayan ve dünya üzerinde en çok atıf alan çalışmaların hadis ilmi açısından dikkat çeken yönleri paylaşılarak araştırmacılara ve kurumlara önerilerde bulunulacaktır. ${ }^{10} \mathrm{Uz}$ manlık alanımız olmadığı için incelenen araştırmalarda kullanılan naif bayes, karar ağaçları, K-en yakın komşu gibi algoritma sınıflandırıcıları ve bilgisayar ile matematik alanında kullanılan diğer teknik terimlerden bahsetmedik. Teknik detaylar hakkında ileri okumalar yapmak isteyen okuyucular, dipnotlarda verdiğimiz kaynaklara başvurabilirler.

\section{Hadis Metinlerine Yönelik Çalışmalar}

Hadis metinlerini merkeze alan çalışmalar veri madenciliğinin alt dalı sayılabilecek metin madenciliği (text mining) ${ }^{11}$ teknikleri kullanılarak yapılmaktadır. Metin madenciliğinde, serbest metin halindeki verilerin formatlanarak nitelikli bilginin çıkarılması amaçlanmaktadır. Metin verileri yapılandırılırken metinleri sınıflandırmak, metinlerden konu çıarmak ve metni özetlemek gibi hedefler belirlenir. $\mathrm{Bu}$ süreçte heceleri analiz etme, kelimelerin frekans dağılımlarını hesaplama ve örüntü tanıma gibi yöntemler kullanılmaktadır. ${ }^{12}$

6 Mohammed Q. Shatnawi vd., "Verification Hadith Correctness in Islamic Web Pages Using Information Retrieval Techniques", International Journal of Computer Applications 44/13 (2012), 47-49.

7 Syuhairah Rahifah Mohammad Najib vd., "Comparative Study of Machine Learning Approach on Malay Translated Hadith Text Classification Based on Sanad", MATEC Web of Conferences 135 (2017), 1-9; Muhammad Yuslan Abu Bakar vd., "Multi-Label Topic Classification of Hadith of Bukhari (Indonesian Language Translation) Using Information Gain and Backpropagation Neural Network", International Conference on Asian Language Processing (2018), 344-350.

8 Amirrudin Kamsin vd., "Developing the Novel Quran and Hadith Authentication System", International Conference on Information and Communication Technology for The Muslim World (2014), 1-5.

9 İbrahim Canan tarafından tercüme edilen Kütüb-i Sitte'nin veritabanını sağlayan http://muhaddis.org/gibi.

102019 yılına kadar yapılan hadis alanındaki algoritmik çalışmalar ve bunların teknik detayları hakkında bk. Aqil M. Azmi vd., "Computational and Natural Language Processing Based Studies of Hadith Literature: A Survey" Artificial Intelligence Review 52/2 (August 2019), 1369-1414; Ibrahim Bounhas, "On the Usage of a Classical Arabic Corpus as a Language Resource: Related Research and Key Challenges", ACM Transactions on Asian and Low-Resource Language Information Processing 18/3 (July 2019), 1-45.

11 Metin veri madenciliği (Text Data Mining), Metin Veri Tabanlarından Bilgi Keşfi (Knowledge Discovery from Textual Databases) gibi isimler de verilmektedir.

12 Sadi Evren Seker, “Metin Madenciliği (Text Mining)", Yönetim Bilişim Sistemleri Ansiklopedisi 2/3 (2015), 30. 
Metin madenciliğinde veri olarak ele alınan metinler genelde doğal dilde yazılan kaynaklardır. ${ }^{13} \mathrm{Bu}$ sebeple metin madenciliği çalışmaları sıklıkla doğal dil işleme (natural language processing, NLP) yöntemleri ile yürütülmektedir. Bilgisayar bilimi ve dil biliminin alt dallarından olan doğal dil işleme, doğal dildeki metinlerin yahut seslerin bilgisayar ortamına işlenmesine yönelik bir çalışmadır. Bu işlem esnasında ses dalgaları tanımlanarak metne, metinler ise sese dönüştürülebilmektedir. Buna ilaveten işlenen dilin söz dizimi, anlamı ve biçimi çözümlenmektedir. Ayrıca yazım hatalarının denetlenmesi ve özet çıkarımı gibi farklı uygulamalar da kullanılmaktadir. ${ }^{14}$

Metin madenciliği bağlamında hadis metinlerini merkeze alan ilk çalışmalar, senedlerini hazfederek hadisleri tasnif etmeye yönelik yöntemler geliștirmeyi amaçlamıştır. ${ }^{15}$ Araştırmacılar senedlerin yanı sıra harekeleri de kaldırmış ve hadis metinlerinden yalnızca Hz. Peygamber'e ait olan ifadeleri almışlardır. Bu işlemlerin ardından kullanılacak model algoritmalarına araştırmacılar tarafından belirlenen hadis metinleri işlenmektedir. Sonuçta, araştırmaya konu olan hadis metinlerini, hadis kaynağındakine uygun olacak şekilde sınıflandırabilen algoritma modellerinin değerlendirilmesi yapılmaktadır. Yapılan çalışmalar veri madenciliği model algoritmalarının başarıları hakkında birçok teknik detay vermektedir. ${ }^{16}$ Bununla birlikte çalışmalarda başarısız olunan hususları zikretmek hadis metinlerinin makine öğrenmesindek ${ }^{17}$ durumunu daha anlaşlır kılacaktır.

Hadis metinlerinin tasnifi üzerine ilk çalışmalar $1^{18}$ da yürüten Al-Kabi araştırmalarından birinde ekibi ile Sahîh-i Buhârînin abdest, ezan, namaz, oruç ve zekât kitaplarından seçtiği 474 hadisin senedlerini hazfedip hadis metinlerinden yalnızca Hz. Peygamber'e ait ifadeleri almış ve bu şekilde metinleri sınıflandırmayı hedeflemiştir. Fakat o, hadislerden yalnızca Hz. Peygamber'in sözleri alınınca metinlerin tasnifi konusunda kısmen başarısız olunduğu ifade etmiştir. Bu hadislerden biri Buhârînin (öl. 256/870) Sahîh'inin "Namaz" kitabına aldığı "Mescid Yapmak Konusunda Yardımlaşmak" babı altındaki hadistir. Rivayete göre Ebû Saîd el-Hudrî (öl. 74/693-94) ve beraberindekiler mescid yapımı esnasında birer kerpiç taşırken Ammâr b. Yâsir

13 Teknik olarak doğal dil “yapay olmayan dil” demektir. (Atakan Altınörs, Dil Felsefesi Sözlüğü (ìstanbul: Paradigma Yayınları, 2000), 84.

14 İstanbul Teknik Üniversitesi (ïÜ), “iTÜ Doğal Dil İşleme Grubu” (Erişim 7 Haziran 2021).

15 Al-Kabi vd., "Al-Hadith Text Classifier", 584-587.

16 Khitam Jbara, "Knowledge Discovery in Al-Hadith Using Text Classification Algorithm", Journal of American Science 6/11 (2010), 409-419.

17 "Makine öğrenmesi (ML), bir bilgisayarın doğrudan yönergeler olmadan öğrenmesine yardımcı olmak için matematiksel modelleri kullanma işlemidir. Bu, yapay zekanın (AI) bir alt kümesi olarak kabul edilir. Makine öğrenmesi, verilerdeki kalıpları belirlemek için algoritmaları kullanır. Tahmin yapabilen bir veri modeli oluşturmak için de bu kalıplar kullanılır. Tıpkı insanların daha fazla alıştırma yaptıkça gelişmesi gibi, veri ve deneyim miktarı arttıkça makine öğrenmesinin sonuçları da daha doğru hale gelir." Microsoft Azure, “Makine Öğrenmesi Nedir?” (Erişim 20 Ağustos 2021).

18 Al-Kabi'nin çalışması, bu konuda araştırma yapan diğer isimler ve araştırma detayları için bk. Mohammad Arshi Saloot vd., "Hadith data Mining And Classification: A Comparative Analysis", Artificial Intelligence Review 46/1 (2016), 113-128. 
(öl. 37/657) ikişer kerpiç taşımaktadır. Bu durumu gören Hz. Peygamber: "Vah Ammâr vah! Onu azgın (bâgî) bir topluluk öldürecek. Ammâr onları cennete çağıracak fakat onlar Ammar'ı cehenneme davet edecek." buyurur. Ammâr b. Yâsir de: "Fitnelerden Allah'a sığınırım." diye dua eder. ${ }^{19}$ Görüldüğü üzere buradaki hadis metninden yalnızca Hz. Peygamber'in sözleri alındığında mevzunun namazla bir alakası olmamaktadır. Bu sebeple bağlamından koparmadan metinleri kategorize etme üzerine yeni çalışmaların yapılması gerektiği ifade edilmiştir. ${ }^{20}$ Bir diğer örnek ise yine Buhârînnin "Namaz" kitabındaki "Mescide Girildiğinde Okların Uçlarını Tutmak" babında yer almaktadır. Rivayete göre birisi demirden uçları bulunan ve kınından uçları çıkmış bu oklar ile mescide girer. Onu gören Hz. Peygamber: "Okların demirlerine sahip çı/okların demir uçlarını tut." buyurur. ${ }^{21}$ Bu metinden de yalnızca Hz. Peygamber'in sözünden namaz yahut mescide dair bir tasnife ulaşllamamaktadir. ${ }^{22}$

Neticede zikredilen hataları ortadan kaldırmayı hedefleyen ve bu konunun uzmanlarından Fouzi $\mathrm{Harrag}^{23}$ gibi isimler Arapça metinleri makine öğrenmesi yoluyla kategorize etme ve bu minvalde dijital hadis sözlükleri oluşturma konusunda çalışmalarını sürdürmektedir. ${ }^{24} \mathrm{Bu}$ çalışmalar meyvelerini verdiğinde hadis metinlerine ulaşmak için arama motorlarından faydalanan İslam hukuku, İslam tarihi ya da başka bir ilahiyat alanında çalısma yapan araştırmacılar hem zamandan kazanmış hem de güvenilir hadis bilgisine ulaşmış olacaktır.

\section{Hadis Ricâline Yönelik Çalışmalar}

Râvi merkezli araştırmaların büyük çoğunluğu sosyal ağ analizi teknikleri kullanılarak yapılmaktadır. Sosyal ağ analizi sosyal aktörler ve bu aktörlerin ilişkileri, bu ilişkilerin oluşturduğu sosyal yapı, aktörlerin bu yapı içerisindeki konumu, konumun özellikleri, bu özelliklerin aktörlere etkileri gibi birçok mülahaza hakkında nicel bilgiler elde edebileceğimiz bir yöntemdir. Hikâyesi 1930'lu yıllara dayanan ve ABD'deki bir kız öğrenci yurdundan kaçan öğrencilerin bu davranışlarını anlamak için yapılan sosyal ağ analizi araştırmaları 1990'lı yıllarda yaygınlık kazanmıştır. ${ }^{25}$

19 Ebû Abdillâh Muhammed b. İsmail el-Buhârî, Sahîhü'l-Buhârî, nşr. Mustafa Dib el-Buga (b.y.: Dimaşk: Dâru İbn Kesîr; Beyrût: el-Yemâme, 1990/1410), "Salât”, 63 (No. 447).

20 Mohammed N. Al-Kabi vd., "Extended Topical Classification of Hadith Arabic Text", International Journal on Islamic Applications in Computer Science and Technology 3/3 (2015), 13-23.

21 Buhârî, "Salât", 66 (No. 451).

22 Al-Kabi vd., "Extended Topical Classification of Hadith Arabic Text”, 13-23.

${ }^{23}$ Fouzi Harrag'ın yaptı̆̆ı çalışmalardan bazıları için bk. Fouzi Harrag - Eyas El-Qawasmah, "Neural Network for Arabic Text Classification", International Conference on the Applications of Digital Information and Web Technologies (2009), 778-783; Fouzi Harrag vd., "Improving Arabic Text Categorization Using Decision Trees", International Conference on Networked Digital Technologies (2009), 110-115.

24 Hadis metinleri üzerine yapılan algoritmik araştırmalardan birkaçı: Manar Alkhatib, "Classification of Al-Hadith Al-Shareef Using Data Mining Algorithm", European, Mediterranean and Middle Eastern Conference on Information Systems (2010); Fouzi Harrag, "Text Mining Approach for Knowledge Extraction in Sahîh Al-Bukhari”, Computers in Human Behavior 30 (January 2014), 558-566.

25 Mehmet Gençer, “Sosyal Ağ Analizi Yöntemlerine Bir Bakış”, Yildiz Social Science Review 3/2 (2017), 20. 
Râvi zincirinin ağ grafiği temsilini ve arama algoritmasını geliștirmek isteyen bir çalışmada Sahîh-i Müslim'den sahîh râvi zinciri algoritmaları oluşturulmuş ve Sahîhi Buhârî'den seçilen 30 hadis bu algoritmalar üzerinde test edilmiştir. Bu test 18 hadisle ilgili doğru neticeye ulaşırken 12 hadiste hata yapmıştır. 2015 yılında yapılan bu çalışmada veriler www.lidwa.com ağından elde edilmiştir. ${ }^{26}$ Fakat araştırmamız esnasında bahsi geçen sitedeki bilgilere ulaşmak mümkün olmadı. Zira artık bu sitede hadislerin sahîh, zayıf, mütevatir, kutsî, merfû, mevkuf oluşu ve ricâle dair bilgiler veren Endonezyaca "Ensiklopedi Hadits - Kitab 9 Imam" adında Ios, Android ve Windows uygulamaları bulunmaktadır. Bahsi geçen araştırmanın 2016 yılında yayınlandığı dikkate alınırsa günümüze kadar geçen zaman zarfında hadis verilerini mobil uygulamalara dönüştürecek kadar mesafe kat edildiği görülmektedir. ${ }^{27}$

Malezya Hükümeti Temel Araştırma Hibe Programı ile Bilgisayar ve Matematik Bilimleri Fakültesi tarafından desteklenen bir araştırmada ise Sahîh-i Müslim'in tüm hadisleri kullanılmıştır. Araştırma verileri 7748 hadis ve 2094 râvi üzerine inşa edilmiştir. Elde edilen sonuçlarda Sahîh-i Müslim'de diğer râvilere oranla en fazla hadis rivayet eden yedi isim Ebû Hureyre (öl. 58/678), Zührî (öl. 124/742), Süfyân b. Uyeyne (öl. 198/814), Şu'be b. el-Haccâc (öl. 160/776), Hz. Âişe (öl. 58/678), Abdullah b. Ömer (öl. 73/693), íbn Vehb'dir (öl. 197/813). ${ }^{28}$

Tanvir Alam ve Jens Schneider tarafindan Sahîh-i Buhârî râvileri üzerine yapılan bir diğer çalı̧̧mada hadis metinleri www.sunnah.com; hadis rivayetlerinin tamamı www.qaalarasulallah.com; râvi biyografilerinin kısa ayrıntıları (isim, yer, yaşam süresi vb.) www.muslimscholars.info adresinden veri olarak toplanmıştır. Çalışmada Sahîh-i Buhârî'de 1372 râvi tarafından rivayet edilen toplam 7370 hadis tespit edilmiştir. Sahabe neslinden 195, tâbiûn neslinden 588, tebeu't-tâbiîn neslinden 326, sonraki devirden ise 263 râvi tespit edilmiş ve bu isimler şehirleri ve dönemine göre tabloya dönüştürülmüştür. Araştırma neticesinde hadis rivayet merkezleri sahabe döneminde Mekke ve Medine'dir. Tâbiûn ve tebeu't-tâbiîn devrinde bu merkezler Kûfe ve Basra'ya kaymış sonraki asırda da Kûfe ve Basra konumunu korumuştur. Şu'be b. el-Haccâc (öl. 160/776), Sahîh-i Buhârînnin râvi ağındaki en önemli râvi iken Zührî (öl. 124/742) onu takip etmektedir. Süfyân b. Uyeyne (öl. 198/814), Süfyân b. Saîd es-Sevrî (öl. 161/778) ve Ebû Nuaym el-Fazl b. Amr (Dükeyn) (öl. 219/834) Sahîhi Buhârî̀deki üçüncü, dördüncü ve beşinci en önemli râvilerdir. ${ }^{29}$

26 Nursyahidah Alias vd., "Searching Algorithm of Authentic Chain of Narrators in Shahih Bukhari Book", International Conference on Applied Computing, Mathematical Sciences and Engineering (2016), 1-6.

27 Benzeri bir çalışmada Lidwa Pusaka tarafından geliştirilen "Ensiklopedi Hadits - Kitab 9 Imam" adlı uygulamadaki verilerden hareketle Buhârî hadislerinin râvileri üzerine yapılmış ve râvi kurallarını oluşturmak için Peygamber, sahâbe, tâbiîn, etbau't-tâbiîn sıralamasında başarılı olduklarını ifade etmişlerdirler. (Dini vd., "Sequential Pattern Mining of Rawi Hadis (Case Study: Shahih Hadis of Imam Bukhari from Software Ensiklopedi Hadis Kitab 9 Imam)", 1-7.

28 Sumaira Saeed vd., "Social network analysis of Hadith narrators", Journal of King Saud University - Computer and Information Sciences 33/2 (February 2021), 1-9.

29 Tanvir Alam - Jens Schneider, "Social Network Analysis of Hadith Narrators from Sahih Bukhari”, International Conference on Behavioural and Social Computing (2020), 1-5. Benzer çalışmalar için bk. Sekti 
Bilindiği üzere ricâl edebiyatına dair eserlerde kimi zaman birçok müellif aynı kişi için bilgi verirken bu bilgilerin birbiri ile çeliştiği görülmektedir. Râvi merkezli algoritmik araştırmalarla bu şekilde birbirini nakzeden bilgiler ve bu bilgileri nakleden müellifler hakkında daha nicel veriler elde edilebilecektir. Bunun yanı sıra râvilerin yaşadığı coğrafya, zaman dilimi, râvilerin yolculukları, hocaları üzerine yapılacak sosyal ağ analizleri de bizlere farklı bakış açıları sunabilecektir. Nitekim Zehebî'nin (öl. 748/1348) Târîhu'l-İslâm adlı eseri üzerine yapilan bir çalışmada kurumsal olarak vaizlik ele alınmış ve veri madenciliği yöntemlerinden bazıları kullanılmıştır. Bu çalışmada Târîhu'l-İslâm'daki vaizliğe dair kavramlardan, vaizlik yapanların kimliklerinden, vaizlerin yaşadıkları coğrafyaya kadar pek çok bilgi grafikler ve tablolar halinde sunulmuştur. ${ }^{30}$

\section{Hadislerin Sıhhat Tespitine Yönelik Çalışmalar}

Makine öğrenmesi yoluyla hadislerin sıhhat tespitine yönelik çalışmalar evvela araştırmacının kullanacağı tanımları formüle etmesi ile başlamaktadır. Ardından araştırmanın amacına yönelik olarak veriler arasındaki ilişkiler ortaya konulmaktadır.

Syed Irfan Hyder ve Syed Ghazanfar Ahmed tarafından yapılan bir araştırmada râvi zincirlerinin modellenmesi ve böylece hadislerin tasnifini gerçekleştirmek hedeflenmiştir. Çalışmada www.ihsanetwork.org ağındaki râvi bilgileri kullanılmıştır. Buna göre merfû-muttasıl, mevkuf-muttasıl, maktû-muttasıl, mürsel, münkatı', mu'dal, muallak hadislerin her biri, tanımındakine uygun ve algoritmaları kontrol edilebilir şekilde râvi zincirlerinin formülleri oluşturulmuştur. Böylece modellenen bu râvi zincirleri ile hadislerin mütevâtir ve âhâd hadis ayrımlarından hangisine dâhil olabileceğine yönelik ileri çalışmalara öncülük edilmiştir. ${ }^{31}$

Mehdi Ghazizadeh ve ekibi, Şîa'nın kütüb-i erbaasından Küleynîye (öl. 329/941) ait $e l-K a ̂ f f^{32}$ adlı eserin birinci cildini esas alarak yaptıkları çalışmada "bulanık uzman sistemi” (ing. fuzzy expert system) kullanmıștır. Klasik mantık yerine bulanık mantığın kullanıldı̆̆ı bu sisteme, öznel değerlendirmelerden kaynaklanan hataları en aza indirmek için esnek veriler girilmektedir. ${ }^{33}$ Araştırmacılar hadisin muttasıl ve mün-

Kartika Dini vd., "Social Network Analysis of Hadith Narrator (Case Study: Shahih Hadith of Imam Bukhari from Software Ensiklopedi Hadits Kitab 9 Imam)", International Journal of Scientific \& Engineering Research 8/2 (February 2017), 176-180; Muhammad Aurangzeb Ahmad, "Towards the Analysis of Narrative Networks", Computer Science \& Engineering (CS\&E) Technical Reports (2013-05-23), 3-10; Muazzam Ahmed Siddiqui vd., "Extraction and Visualization of the Chain of Narrators from Hadiths", International Journal of Computational Linguistics Research 5/1 (March 2014), 14-25.

30 Maxim G Romanov, Computational Reading of Arabic Biographical Collections with Special Reference to Preaching in the Sunni World (661--1300 CE) (Ann Arbor: University of Michigan, Horace H. Rackham School of Graduate Studies, Doktora Tezi, 2013), 1-369.

31 Syed Irfan Hyder - Syed Ghazanfar Ahmed, “Towards A Database Oriented Hadith Research Using Relational, Algorithmic and Data-Warehousing Techniques”, Al Saqafat-ul-Islamia (Islamic Culture), Research Quarterly Journal of Shaikh Zayed Islamic Center for Islamic and Arabic Studies 19 (2008), 14-32.

32 Küleynî, Ebû Ca'fer Muhammed b. Ya'kub, el-Usûl mine’l-Kâfi (Tahran: Dârü’l- Kütübi'l-İslâmiyye, 1978).

33 Bulanık Uzman Sisteminin tanımı ve uygulanışı hakkında bk. Ahmet Baran vd., "Bulanık Uzman Sistem Yaklaşımı ile Yeşil Kart Başvuru Değerlendirme Sistemi”, Atatürk Üniversitesi İktisadi ve İdari Bilimler Dergisi 24/1 (2010), 63-76. 
katı‘ olmasını bir değişken, râvinin güvenilirlik oranlarını bir başka değişken olarak işlemiştir. Neticede el-Kâfíden elde edilen verilerle el-Kâfîye göre sahîh olduğu söylenen hadisler bu sistemde \%94 oranında doğrulanmıştır. ${ }^{34}$ Böylece ileride yapılacak benzer çalışmalarda bir müellifin, hadisin sıhhati için öne sürdüğü şartları kendi eserinde ne kadar uyguladığını test etmek mümkün olacaktır.

Najiyah ve ekibi tarafından yapılan bir başka çalışmada ise hem metin hem de râvi veri olarak alınmış ve hadisler "sahîh, mevzu, zayıf-metrûk, zayıf-münker, zayıfmuallel, zayıf-müdrec, zayıf- maklûb" gibi 19 dereceye ayrıldıktan sonra her bir derece kodlanmıştır. Ardından araştırmacılar, râvisinin bid'at sahibi olması, unutkan olması, senedinin sonunun hazfedilmesi veya başının hazfedilmesi gibi niteliklerine göre hadisleri 40 farklı kategoride değerlendirmeye almışlardır. Böylece uzman sistemler ve basit algoritmalar kullanarak hadis veri tabanı oluşturmak ve araştırmada modellenen düzeylere göre hadisleri sınıflandırmak hedeflenmiş olup büyük oranda başarı sağlanmıştır. ${ }^{35}$

Aldhaln'ın öncülük ettiği geniş kapsamlı başka bir çalışmada ise sahîh hadis tanımında yer alan ifadeler formüle edilmiş ve bu formüllerin altına, uygun düşecek şekilde, râviler için kullanılan cerh ve tadil lafizları girilmiştir. Böylelikle râvinin durumu ve hadisin sıhhati birbirine bağlantılı olacak şekilde sorgulanabilir hale gelmiştir. Çalışma Buhârînnin (öl. 256/870) el-Câmiu's-sahîh'i, Tirmizînnin (öl. 279/892) el-Câmiu's-sahîh'i ve Nâsırüddin el-Elbânînin (1914-1999) Silsiletü'l-ehâdîsi'd-daîfe eserleri merkeze alınarak yapılmıştır. Çalışmayı gerçekleştiren araştırmacılar bahsi geçen müelliflerin râviler konusunda farklı değerlendirmelerde bulunduğunu belirtmektedir. Bu sebeple önerdikleri modelin tüm muhaddislerin ortak yöntemi olmad1ğını ifade etmektedirler. ${ }^{36}$

\section{Hadisin Web Ortamında Kullanımına Yönelik Çalışmalar}

Küresel erişim sayesinde birçok farklı dili kullanan ve farklı dine mensup insanlar hadis metinlerine ulaşabilmektedir. Bu sebeple hadislerden bilgi çıkarımını kolaylaştırmak için web tabanlı tercüme hadis metinleri üzerine yapılan çalışmalar dikkat çekmektedir. Bu konuda araştırmacıların genel olarak ifade ettiği sıkıntı hadis veri külliyatının olmayışıdır. ${ }^{37}$ Bu sebeple araştırmacılar ya mevcut web sayfalarını yahut kendi oluşturdukları veri tabanlarını kullanmaktadır.

34 Mehdi Ghazizadeh vd., "Fuzzy Expert System in Determining Hadith Validity", Advances in Computer and Information Sciences and Engineering, ed. Tarek Sobh (Springer Science-Business Media B.V., 2008), 354-359.

35 Ina Najiyah vd., "Hadith Degree Classification For Shahih Hadith İdentification Web Based", International Conference on Cyber and IT Service Management (2017), 1-6.

36 Kawther Aldhaln vd., "Improving Knowledge Extraction of Hadith Classifier Using Decision Tree Algorithm", International Conference on Information Retrieval \& Knowledge Management (2012), 148-152. Ayn1 ekip bu makalenin daha fazla teknik ayrıntıyı içeren genişletilmiş bir halini yayınlamışlardır. Kawther Aldhaln vd., "Novel Mechanism to İmprove Hadith Classifier Performance", International Conference on Advanced Computer Science Applications and Technologies (2013), 512-517.

https://doi.org/10.1109/ACSAT.2012.93.

37 Shatnawi vd., "Verification Hadith Correctness in Islamic Web Pages Using Information Retrieval Techniques”, 47-50. 
2012 yılında yapılan bir çalışmada Elbânînnin resmî web sayfasından Silsiletü'lehâdîsi'd-daîfe ve Silsiletü'l-ehâdîssi's-sahîha adlı eserler veritabanı olarak belirlenmiştir. ${ }^{38}$ Çalş̧maya göre bu iki eserdeki 17000 hadisin 11.083 'ü "sahîh", 2.878'i zayılf, 1542'si “hasen", 848'i “mevzu”, 537'si “dâ̂fu'n-cidden", 288'i “münker" olacak şekilde indekslenmiștir. Bilindiği üzere kimi zaman zayıf bir hadisin metni ile sahîh bir hadisin metni aynı olabilmektedir. İşte bu sebeple bahsi geçen çalışmada bu husus sorun oluşturmuş ve araştırmacılar, indekslemenin bir hadis uzmanı ile çalışarak yapılması gerektiği sonucuna varmışlardır. ${ }^{39}$

Urduca, Malayca, Endonezyaca ve İngilizce ${ }^{40}$ hadis metinlerinin web sayfalarındaki tercümelerine odaklanan ve hadis tercümelerini sahih hadis metinlerine ulaştırmayı hedefleyen çalışmalar ise daha ziyade "varlık ismi tanıma (named entity recognition [NER])" yöntemi üzerinedir. Bu yöntemde bir metnin içerisinde kişi, kurum, yer ve zaman gibi sınıflar, üzerinde çalışılan metnin diline bağımlı olacak şekilde bulunabilmektedir. ${ }^{41}$ Böylece orijinal dili Arapça olan hadislerin başka dillerdeki tercümelerine odaklanılarak daha fazla kazanım sağlanması hedeflenmektedir. Fakat bu tercümelerden yapılandırılmış șekliyle yararlanmak isteyen araştırmacılar öncelikli olarak web merkezli hadis veri tabanı belirlemişlerdir. Bu minvalde yapılan bir araştırmada Sahîh-i Buhârînin Urduca tercümesi için veri tabanı olarak www.islamicurdubook.com adresi kullanılmıştır. ${ }^{42}$ Malayca'ya çevrilen hadislerin, senedine göre tasnifi üzerine yapılan bir çalışmay ${ }^{43}$ incelerken rastlanan, Malezya Mara Teknoloji Üniversitesi'nin resmî web sayfasında yer alan, sigir.uitm.edu. my/webhadis bağlantısı hadis ve teknoloji odaklı araştırmaların akademik kanallar vasitasıyla yürütülmesi adına sevindiricidir.

Bunun yanı sıra bir araştırma farklı web sitelerinden hadis verilerini toplayarak kullanıcıların herhangi bir hadis kitabını veri seti olarak indirebilecekleri hem merkezî hem de çok dilli veri deposu olarak hizmet veren bir web sayfası oluşturmayı hedeflemektedir. Çalışmayı yapan ekip Sahîh-i Müslim’i http://sunnah.com/muslim; Ebû Dâvûd'un Sünen'ini http://ahadith.co.uk/; Mâlik'in Muvattâ'ını http://ahadith. co.uk/maliksmuwatta; Sahîh-i Buhârî̀yi http://www.Sahîh-bukhari.com/ ve http:// hadithcollection.com adlı İngilizce-Arapça hadis yayını yapan sitelerden almıştır. ${ }^{44}$

38 Bahsi geçen makalede 2011 tarihine atıf yapılan www.alalbany.net adlı web sitesinde şu anda ilgili eserler bulunmamaktadır.

39 Shatnawi vd., "Verification Hadith Correctness in Islamic Web Pages Using Information Retrieval Techniques", 47-50.

40 Mohanad Jasim Jaber - Saidah Saad, "NER in English Translation of Hadith Documents Using Classifiers Combination", Journal of Theoretical and Applied Information Technology 84/3 (February 2016), 348-354.

${ }^{41}$ Zeynep Banu Özger - Banu Diri, "Türkçe Dokümanlar İçin Kural Tabanlı Varlık İsmi Tanıma”, Türkiye Bilişim Vakfi Bilgisayar Bilimleri ve Mühendisliği Dergisi 5/2 (Haziran 2016).

42 Ahsan Mahmood vd., "Query Based İnformation Retrieval and Knowledge Extraction Using Hadith Datasets", International Conference on Emerging Technologies (2017), 1-6.

43 Mohammad Najib vd., "Comparative Study of Machine Learning Approach on Malay Translated Hadith Text Classification based on Sanad", 1-7.

44 Ahsan Mahmood vd., "A Multilingual Datasets Repository of the Hadith Content", International Journal of Advanced Computer Science and Applications 9/2 (2018), 165-171. 
Benzeri bir web sitesi çalışması Prens Muhammed b. Selman'ın hayır kurumu sponsorluğunda gerçekleştirilen https://hadeethenc.com/ projesi adı altında yapılmaktadır. Bahsi geçen sitede Türkçe dâhil 20 dilde hadis tercümeleri veri tabanı oluşturulmaya devam edilmektedir.

\section{Sonuç}

Teknolojinin gelişmesi ile insanlar hadis metinlerine web sayfalarından veya mobil uygulamalardan rahatlıkla ulaşmaktadır. Kolay ulaşılabilen büyük miktardaki bu hadis bilgisi bizatihi dijital veri olmasının yanı sıra bilgiyi ulaştıran ve bilgiye ulaşan insan profili açısından kıymetlidir.

Genel olarak sosyal bilimlerde özel olarak hadis alanındaki verileri yapılandırarak fen bilimlerinde olduğu gibi hesaplanabilir ve nesnel bir şekilde ortaya koymak önemli bir firsattır. Peter Drucker'a atfedilen meşhur sözde olduğu gibi ölçemediğimiz bir şeyi yönetemeyiz. Esasında asırlar öncesinde muhaddislerin de yapmaya çalıştığı bir nevi ölçme, değerlendirme ve neticede yönetmedir. Yönetilmek istenen sünnetin unutulması ve tahrip edilmesinin önüne geçmektir. Ölçülmek istenen ise hadisin ricâli olup buna paralel olarak hadisin değerlendirilmesidir. Fakat bu değerlendirmeler bazen muhaddisin kişisel yorumları olarak karşımıza çıkmaktadır. İşte bu noktada kimi zaman yoruma dayalı ve kendini tekrar eden malumatlar yerine somut verilere dayanan çalışmalar bu alana yeni bir soluk kazandıracaktır. Örneğin her bir cerh ve ta'dîl uzmanının yöntemi algoritmalarla raporlanabilir. Elde edilen sayısal verilerle râviler üzerindeki sosyal etkiler ölçümlenir. Böylece sayısal verilerle cerh ve ta'dîl üzerine çalışmalar yapanların kanaatleri mukayese edilir. Bu mukayesenin neticesi bizlere yeni bakış açıları sunabilir. Bir diğer örnek ise hadis usulü üzerinden verilebilir. Malum olduğu üzere hadis usûlünün çatısını İbn Hacer (öl. 852/1449) inşa etmiştir. Dikkatle okunduğunda onun usûl tasnifinde mantık ilkelerinden faydalandığı görülecektir. Algoritmalar yardımı ile usûl eserleri üzerinden elde edilen sayısal veriler belki İbn Hacer'i doğrulayacak böylece o, güven tazelemiş olacaktır. Bununla birlikte yeni usûl tanımları yapmamız bile gerekebilecektir. Fakat tüm bu çalışmalar için sağlam bir hadis bilgisi gerekmektedir. Zira klasik metinlerin dilini dijital dile uygulama esnasında yapılan bir yanlış bizlere hatalı veriler sunacaktır. Bu bahsedilenlerden hareketle;

1. "Hadis Araştırma Merkezleri" kurulması önerilebilir. Bu merkezlerde hadis verilerini işleyecek bilgisayar ve matematik uzmanları ile hadis ilmi mütehassısları iş birliği içerisinde birçok proje geliştirip bu projelere hayat verebilirler.

2. Bizim önerebileceğimiz projelerden biri kurumsal bir web sayfası altında hadis veri tabanı oluşturulmasıdır. Elbette bu veri tabanı yalnızca Arapça hadis metinlerini ihtiva etmeyip işinin ehli mütercimler tarafından tercüme edilmiş, anlaşılır Türkçe metinleri de barındırmalıdır. İlgili sayfada aranılan hadisin sahîh, hasen yahut zayıf olmasından kudsî, merfû ya da mevkûf olmasına kadar birçok usul bilgisi de verilmelidir.

3. Bir başka proje olarak râvi veri tabanı oluşturulması önerilebilir. Bu projenin faydalarından biri bilhassa ilahiyat alanında yapılan bilimsel çalışmalardaki Latinize 
edilmiş râvi isimleri ve biyografileri üzerinde mutabık bir başvuru kaynağı sağlanmış olmasidır.

4. Ayrıca bu projeleri hayata geçiren ekipler usul kitaplarındaki ıstılahî tanımların makine öğrenmesi yoluyla ne kadar doğrulanabildiği ve bu terimlerin yeni anlamlar kazanıp kazanamayacağı; hadis metinlerinin indekslenmesi ile konu odaklı çalışmalara ne kadar fayda sağlanabileceği; râvi değerlendirmelerindeki sübjektifliğin ya da taassubun ölçülebilirliği gibi hadis alanıyla alakalı birçok farklı araştırma yapabilir ve bizlere elde edilen somut verilerle yeni ufuklar kazandırabilirler.

Önerilen bu projelerin yıllarca süreceği muhakkaktır. Fakat geç atılan her adım ülkemizin hadis ilim merkezlerinden biri olma ihtimalinden uzaklaşması demektir. Nasıl ki bir zamanlar Medine, Kûfe ve Basra hadis ilim merkezi olmuşlarsa artık modern hadis veri tabanı teknolojisini oluşturan devletler/fakülteler/kurumlar bu merkeze ev sahipliği yapacaktır. Bu da bilimsel cazibe merkezi olma yarışını teşvik edecek ve hadis ilmi gelişmeye devam edecektir. Nitekim bunu keşfeden başta Suudi Arabistan ve Birleşik Arap Emirlikleri olmak üzere Pakistan, Endonezya, Malezya ve İran bünyesindeki farklı kurumlar kendi araştırmalarında kullanmak ve tüm Müslümanların hizmetine sunmak adına hadis veri depoları oluşturmaya başlamıştır. Ülkemizde ise akademik yahut kurumsal anlamda böyle bir çalışma bilindiği kadarıyla mevcut değildir. Diyanet İşleri Başkanlı̆̆ı tarafından yayınlanan ve online erişimi de mümkün olan "Hadislerle İslam" adlı eserde konuları açısından bir kısım hadislere ulaşılabilmektedir. Fakat eserin online erişimdeki hali veri tabanı sorgulamaları açısından pratik değildir.

Bu konudaki bir başka husus ise hadis metnine dijital ortamdan ulaşan halktır. Daha önce değindiğimiz birkaç araştırmalarda görüldüğü üzere hadis karşıtı web siteleri hadis hakkında bilgi sahibi olmak isteyen öğrenciler tarafından sıkça ziyaret edilmektedir. Bu sebeple halkın ulaştığı hadis verilerinin içeriği hakkında bilgi edinme bilincini kazanması, yanlış din algısından kaynaklanan sosyal ve politik birçok problemin çözüme kavuşturulmasına yardımcı olacaktır. Nitekim Büyük Selçuklu veziri Nizâmülmülk’ün (öl. 485/1092) hicrî beşinci asırda Şiî-Bâtınî düşünce karşısında Sünnîliği yayıp güçlendirme faaliyetlerini eğitim aracıllı̆̆ ile gerçekleştirdiği bilinen bir gerçektir. Yirmi birinci asra gelindiğinde ise doğru din algısına hizmet edecek eğitim kurumları ve faaliyetlerinin güncellenmesi gerektiği aşikârdır. $\mathrm{Bu}$ vesile ile Hindistanlı hadis âlimi Muhammed Mustafa Âzamî (öl. 2017) rahmetle yâd edilmelidir. Zira kendisi dijital hadis kütüphanesi oluşturmak amacıyla yola çıkmış ve 1970li yıllardan itibaren Arap alfabesini destekleyen bilgisayarlara ulaşılması için büyük uğraşlar vermiştir. Aradan geçen yıllar içerisinde oğlu Aqil M. Azmi ile veri madenciliği tekniklerini Arapça metinler başta olmak üzere hadis ilmine de uygulamıştır. Böylece onlar gibi bu sahada çalışmalar yapan araştırmacılar, İslam'ın temel kaynaklarından biri olan hadise internet veya dijital uygulamalarla erişen milyonlarca kullanıcının ulaştıkları içeriklerin bazen sıhhatini bazen de anlamını kontrol edebilecekleri platformlar oluşturmak için çabalamaktadır. Elbette ulaşılan bazı sahih hadisler tartışma konusu olabilecektir. Fakat bu tartışmalara hadis karşıtı gruplar 
tarafından değil de meslekten bilim insanlarının yön vermesinin faydalı olacağı kanaatindeyiz.

Tüm bunların yanı sıra fen bilimlerinde bile deney ve gözleme dayalı araştırmalar bilim insanının yorumuna bağlıdır. Söz konusu sosyal bilimler olunca yorumsallıktan tamamen uzak olmak mümkün değildir. Hadisin de bir parçası insandır, râvidir. Râvinin sabit ve değişmez bir veri olarak görülemeyeceği aşikârdır. Bu sebeple hadisi hesaplamalı bir bilim olarak görmek pek mümkün gözükmemektedir fakat öznellik en aza indirilebilir. Sayllan bu olumlu ve olumsuz yönlerin sonuçları zaman içerisinde yapilan araştırmalarla açı̆̆a çıkacaktır.

\section{Kaynakça}

Abdul Karim, Nor Shahriza - Hazmi, Norzelatun Rodhiah. “Assessing Islamic Information Quality on the Internet: A Case Of Information About Hadith". Malaysian Journal of Library \& Information Science 10/2 (December 2005), 51-66.

Abu Bakar, Muhammad Yuslan vd. "Multi-Label Topic Classification of Hadith of Bukhari (Indonesian Language Translation) Using Information Gain and Backpropagation Neural Network". International Conference on Asian Language Processing (2018), 344-350. https://doi.org/10.1109/IALP.2018.8629263

Alam, Tanvir - Schneider, Jens. "Social Network Analysis of Hadith Narrators from Sahih Bukhari". International Conference on Behavioural and Social Computing (2020), 1-5. https://doi.org/10.1109/BESC51023.2020.9348299

Aldhaln, Kawther vd. "Improving Knowledge Extraction of Hadith Classifier Using Decision Tree Algorithm". International Conference on Information Retrieval \& Knowledge Management (2012), 148-152. https://doi.org/10.1109/InfRKM.2012.6205024

Alias, Nursyahidah vd. "Searching Algorithm of Authentic Chain of Narrators in Shahih Bukhari Book". International Conference on Applied Computing, Mathematical Sciences and Engineering (2016), 1-6.

Al-Kabi, Mohammed N. vd. "Extended Topical Classification of Hadith Arabic Text”. International Journal on Islamic Applications in Computer Science and Technology 3/3 (2015), 13-23.

Al-Kabi, Mohammed N. vd. "al-Hadith Text Classifier". Journal of Applied Sciences 5/3 (2005), 584-587. https://dx.doi.org/10.3923/jas.2005.584.587

Altınörs, Atakan. Dil Felsefesi Sözlügü̈. İstanbul: Paradigma Yayınları, 2000.

Azmi, Aqil M. vd. Al-Qabbany, Abdulaziz O. - Hussain, Amir. "Computational and natural language processing based studies of hadith literature: a survey". Artificial Intelligence Review 52/2 (August 2019), 1369-1414. https://doi.org/10.1007/s10462-019-09692-w

Bounhas, Ibrahim. "On the Usage of a Classical Arabic Corpus as a Language Resource: Related Research and Key Challenges". ACM Transactions on Asian and Low-Resource Language Information Processing 18/3 (July 2019), 1-45. https://doi.org/10.1145/3277591

Buhârî, Ebû Abdillâh Muhammed b. İsmail. Sahîhü'l-Buhârî. nşr. Mustafa Dib el-Buga. 6 cilt. b.y.: Dımaşk: Dâru İbn Kesîr; Beyrût: el-Yemâme, 4. Basım, 1990/1410.

Gençer, Mehmet. “Sosyal Ağ Analizi Yöntemlerine Bir Bakış”. Yildiz Social Science Review 3/2 (2017), 19-34.

Hyder, Syed Irfan - Ahmed, Syed Ghazanfar. "Towards A Database Oriented Hadith Research Using Relational, Algorithmic and Data-Warehousing Techniques”. Al Saqafat-ul-Islamia (Islamic Culture), Research Quarterly Journal of Shaikh Zayed Islamic Center for Islamic and Arabic Studies 19 (2008), 14-32. 
Jaber, Mohanad Jasim - Saad, Saidah. "NER in English Translation of Hadith Documents Using Classifiers Combination". Journal of Theoretical and Applied Information Technology 84/3 (February 2016), 348-354.

Jbara, Khitam. "Knowledge Discovery in Al-Hadith Using Text Classification Algorithm”. Journal of American Science 6/11 (2010), 409-419. http://www.dx.doi.org/10.7537/marsjas061110.48

Mahmood, Ahsan vd. "A Multilingual Datasets Repository of the Hadith Content". International Journal of Advanced Computer Science and Applications 9/2 (2018), 165-171. https://dx.doi.org/10.14569/IJACSA.2018.090224

Mahmood, Ahsan vd. "Query Based Information Retrieval and Knowledge Extraction Using Hadith Datasets". 2017 13th International Conference on Emerging Technologies (2017), 1-6. https://doi.org/10.1109/ICET.2017.8281714

Mehdi Ghazizadeh vd. "Fuzzy Expert System in Determining Hadith Validity", Advances in Computer and Information Sciences and Engineering, ed. Tarek Sobh (Springer ScienceBusiness Media B.V., 2008), 354-359. https://doi.org/10.1007/978-1-4020-8741-7_64

Microsoft Azure. "Makine Öğrenmesi Nedir?". (Erişim 20 Ağustos 2021). https://azure.microsoft.com/tr-tr/overview/what-is-machine-learning-platform/

Mohammad Najib, Syuhairah Rahifah vd. "Comparative Study of Machine Learning Approach on Malay Translated Hadith Text Classification Based on Sanad". MATEC Web of Conferences 135 (2017), 1-9. https://doi.org/10.1051/matecconf/201713500066.

Mohammed Q. Shatnawi vd. "Verification Hadith Correctness in Islamic Web Pages Using Information Retrieval Techniques". International Journal of Computer Applications 44/13 (April 2012), 47-49. http://dx.doi.org/10.5120/6327-8680.

Najiyah, Ina vd. "Hadith Degree Classification For Shahih Hadith İdentification Web Based". International Conference on Cyber and IT Service Management (2017), 1-6. https://doi.org/10.1109/CITSM.2017.8089304.

Özger, Zeynep Banu - Diri, Banu. “Türkçe Dokümanlar İçin Kural Tabanlı Varlık İsmi Tanıma”. Türkiye Bilişim Vakfi Bilgisayar Bilimleri ve Mühendisliği Dergisi 5/2 (Haziran 2016), 3- 11.

Romanov, Maxim G. Computational Reading of Arabic Biographical Collections with Special Reference to Preaching in the Sunni World (661--1300 CE). Ann Arbor: University of Michigan, Horace H. Rackham School of Graduate Studies, Doktora Tezi, 2013). https://deepblue.lib.umich.edu/handle/2027.42/102300.

Saeed, Sumaira vd. "Social network analysis of Hadith narrators". Journal of King Saud University-Computer and Information Sciences 33/2 (February 2021), 1-9. https://doi.org/10.1016/j.jksuci.2021.01.019.

Saleh, Adam Gambo - Mai, Mohammed. "Assessment of the Quality of Hadith Information on the Internet”. Information Impact 6/2 (2015), 127-138.

Saloot, Mohammad Arshi vd. "Hadith data Mining And Classification: A Comparative Analysis". Artificial Intelligence Review 46/1 (2016), 113-128. https://doi.org/10.1007/s10462-016-9458-x.

Savaş, Serkan vd. “Veri Madenciliği ve Türkiye'deki Uygulama Örnekleri”. İstanbul Ticaret Üniversitesi Fen Bilimleri Dergisi 11/21 (Bahar 2012), 1-23.

Seagate. "Rethink_Data_Report_2020". (Erişim 3 Haziran 2021). https://www.seagate.com/files/www-content/our-story/rethink-data/files/Rethink_Data _Report_2020.pdf

Seker, Sadi Evren. “Metin Madenciliği (Text Mining)”. Yönetim Bilişim Sistemleri Ansiklopedisi 2/3 (2015), 30.

Sekti Kartika Dini vd. "Sequential Pattern Mining of Rawi Hadis (Case Study: Shahih Hadis of Imam Bukhari From Software Ensiklopedi Hadis Kitab 9 Imam)". AIP Conference Proceedings 1827/1 (2017), 1-8. https://doi.org/10.1063/1.4979446 